This is an Accepted Manuscript (post print version) of an article published by Taylor \& Francis Online in Journal of Children and Media on 16/08/2020, available online:

https://www.tandfonline.com/doi/full/10.1080/17482798.2020.1809481

\title{
Introducing the Social Media Literacy (SMILE) Model with the Case of the Positivity Bias on Social Media \\ Lara Schreurs (MSc) $)^{1-2}$ and Laura Vandenbosch $(\mathrm{PhD})^{1}$
}

Affiliations: ${ }^{1}$ School for Mass Communication Research, Faculty of Social Sciences, KU Leuven, Leuven Belgium; ${ }^{2}$ Research Foundation Flanders (FWO-Vlaanderen), Belgium;

Email addresses: lara.schreurs@kuleuven.be; laura.vandenbosch@kuleuven.be;

Please cite as follows: Schreurs, L., \& Vandenbosch, L. (2020). Introducing the Social Media Literacy (SMILE) Model with the Case of the Positivity Bias on Social Media. Journal of Children and Media. doi:10.1080/17482798.2020.1809481

Correspondence concerning this article should be addressed to Laura Vandenbosch, School for Mass Communication Research, KU Leuven, Parkstraat 45, B-3000 Leuven, Belgium, laura.vandenbosch@kuleuven.be

Conflict of Interest: The authors declare that they have no conflict of interest.

This work was supported by the Research Foundation Flanders (FWO-Vlaanderen) under Grant 11D3119N 


\begin{abstract}
Although current literature has extensively discussed media literacy processes, few theories exist explaining the role of social media literacy. Social media is used daily by a substantial number of young people and may exert an important influence on its users' wellbeings. Considering media literacy, media effects, social psychology, interpersonal communication and educational literature, a novel theoretical framework called the $\underline{\text { Social }}$ Media Literacy (SMILE) model is introduced. This framework was formulated to explain 1) how to conceptualize social media literacy, 2) how social media literacy can change the dynamics between social media and its users and 3) how participatory mediation processes result into social media literacy. The SMILE-model is illustrated against the background of the social media positivity bias. Ultimately, the newly developed guiding framework aims to stimulate more theory-driven research into the scholarly understanding of social media literacy in well-being. Such insights may especially be useful for research in the field of children, adolescents and the media.
\end{abstract}

Keywords: social media literacy, the positivity bias in social media, empowerment, development

Word count: 8995 


\section{Introducing the Social Medịa Literacy (SMILE) Model with the Case of the Positivity}

\section{Bias on Social Media}

Growing concerns from scholars and policy makers about the pervasive usage of social media in the current society echo the scholarly call for more research into effective measures to help especially young social media users get the most out of their social media experiences (Kleemans, Daalmans, Carbaat \& Anschütz, 2018). Within the limited research that mainly exists among young users, social media literacy has recently been suggested as a promising direction in this regard (Tamplin, McLean, \& Paxton, 2018). Daneels and Vanwynsberghe (2017) define social media literacy as "the technical and cognitive competencies users need to use social media in an effective and efficient way for social interaction and communication on the web". Livingstone (2014) emphasizes in her view on social media literacy its potential to help children avoid (privacy) risks and safely explore the opportunities of the online environment. One scholar has conceptualized this concept from a domain-specific area of social media effects and defined it as a critical understanding of both advertisers and peers' motivations and techniques for modifying social media images (Tamplin et al., 2018).

Although these first attempts to conceptualize (and study) social media literacy are valuable, this paper argues that their definitions do not adequately address the complexities that are central within this concept. Social media literacy can be partly embedded in the rich area of literature on media literacy (Daneels \& Vanwynsberghe, 2017), however, the distinctive characteristics of social media (e.g., content creating/editing and exponential opportunities for interactions and social comparisons with 'similar' peers) warrant a unique approach. The different dynamics in which social media literacy operates have not been at the core of previous conceptualizations as these conceptualizations mainly occurred in empirical research and thus did not aim to theoretically explain its role in youth's well-being. 


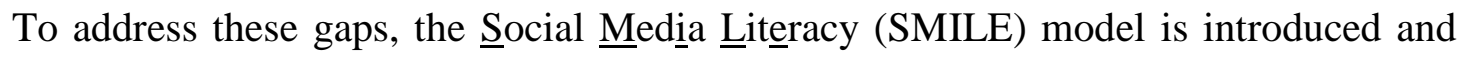
embodies a first guiding framework for social media literacy. The model bridges the literature on (social) media effects with insights from traditional media literacy research, educational and social psychology literature (1) to conceptualize social media literacy, (2) to explain its development, and (3) to describe its role in social media user interactions. The model starts from the idea that social media literacy can maximize the opportunities and minimalize or even prevent the risks of social media use. In its core, the SMILE-model intends to inspire more theory-driven research lines on the role of social media literacy in social media effects, ultimately aiming to contribute to young people's overall well-being.

Moreover, current perspectives on traditional media literacy emphasize that different types of media literacy share several components across the media effects that they each target, but, at the same time, different characteristics exist within each media literacy area (e.g., appearance, sexuality and violence) (Byrne, 2009). Similarly, each area of social media effects is typified by unique dynamics and peculiarities. For example, different characteristics exist for social media effects regarding privacy concerns, safety issues, cyberbullying and body image. Consequently, we illustrate the general model's assumptions for one single area of social media literacy: The positivity bias among adolescents. This area was selected because adolescents are among the most frequent daily users of social media (Anderson \& Jiang, 2018) and during their usage, they interact endlessly with positively biased posts. The positivity bias has increasingly been hold responsible for adolescents' decreased mental well-being (e.g., Kleemans et al., 2018), which is a pertinent public concern in today's society.

\section{Defining the Meaning of Social Media Literacy}

Media literacy fundamentally aims to provide users with the necessary critical autonomy to interact with media in a healthy and responsible way (Aufderheide, 1993). At its core, media literacy will reduce negative media effects and maximize positive ones. In contrast 
to the strong consensus on the value of media literacy, scholars disagree upon the key elements that define this concept with regards to traditional media (Jeong, Cho, \& Hwang, 2012) and social media (e.g., Tamplin et al., 2018; Daneels \& Vanwynsberghe, 2017). To seek direction in this clutter of interpretations, we define social media literacy as follows: "the extent to which cognitive and affective structures are present among users to ensure the risks of interactions with social media content are mitigated and the opportunities are maximized." According to this definition, social media literacy can be seen as a continuous variable with two subcomponents (i.e., cognitive and affective structures) that each are present in varying levels.

The subcomponent of cognitive structures is adopted from Potter's (2004) processing model and extended with insights from social media literature (boyd \& Ellison, 2008). Cognitive structures include sets of organized knowledge in the user's memory that provide the user with sufficient resources to process social media content adequately (Lang, 2017). As such, these structures guide the construction and interpretation of social media content. This knowledge entails different layers of understanding within social media effects. In its most basic level, adolescents are not social media literate and thus do not understand what different types of social media effects are or could be. At an average level, knowledge on the effects exists but is not, or inconsistently, applied. Accordingly, a more passive form of cognitive structures is present as the structures are not always actively applied when using social media. At a high level, adolescents actively use their cognitive structures and interpret, reflect on and understand social media content within its specific context. They thereby empower themselves during their social media experiences. Even more, they act with a sense of responsibility towards other users when developing their own posts.

Part of the cognitive structures are rooted in users' traditional media literacy. Existing knowledge on the commercial intent of media industries (Potter, 2004) can help a user reflect upon the revenue strategies of social media companies, but also companies that use social 
media for profit purposes (Vanwynsberghe, 2014). Understandings of production techniques of traditional media, such as television and magazines (Potter, 2004), are relevant to interpret the sharing of traditionally produced messages on social media. Yet, such understandings will need to be further tailored to the peculiarities of social media (e.g., who shares the video with what intent, what is the meaning of receiving likes, re-posting and comments).

Regarding these peculiarities, social media content is much more personal and selffocused than traditional media content (Perloff, 2014). The audience of social media messages is not conceptualized as heterogeneous or anonymous, but consists of individuals who are similar to the sender. Social media are said to be "fundamentally media of one's peers" (Perloff, 2014, p. 366). These peers are all allowed to directly transmit personal-generated content on social media (Perloff, 2014). Thus apart from being passive recipients of media content - which also occurs very frequently on social media - users can interactively create, edit and share messages within their personal online network by using the platform's instant messaging technology and its tools to post status updates and share photos/videos (Tsitsika et al., 2014).

Due to their interactive nature, social media are eminent tools for interpersonal communication. Users can extend their offline relations online or initiate new social ties. Social media interactions are editable and highly accessible, develop asynchronously, and allow a limited and selective set of social-contextual cues to be present. Because of these affordances, social media interactions differ in their core from offline interactions and impact communication processes and social relationships in different ways (Walther, 2017). Social media literate adolescents have developed cognitive structures on these unique social mediated interpersonal norms and dynamics. Together, cognitive structures of social media literacy include understandings of a) traditional media literacy, b) social media features and c) interpersonal communication dynamics on social media. 
The subcomponent of affective structures refers to sets of organized emotions in the users' memory which guide (spontaneous) emotions in response to using social media. The inclusion of this subcomponent builds upon the insight of traditional media literacy literature that cognitive structures alone are not sufficient to counter adversarial media effects (Austin \& Pinkleton, 2016) and the importance of the capitalization of the positive outcomes that follow from social media interactions (Palmer, Ramsey, Morey, \& Gentzler, 2016). First, traditional media literacy literature argues that although users may be aware of the negative effects of media content, such media content may still spontaneously and thus instinctively appeal to, and even emotionally affect, youth (Gill, 2012). Therefore, being literate cannot be about possessing the 'right' affective responses but instead relates to managing one's affective responses. In this regard, emotion regulation literature has typically distinguished between adaptive and maladaptive strategies to manage one's affective responses, based on the strategies' relations to mental health (Cracco, Goossens, \& Braet, 2017). What characterizes a social media literate user is that he/she would rather apply adaptive than maladaptive strategies when experiencing negative or positive emotions resulting from one's social media usage.

Also, literature on social media and positive well-being specifically suggests that affective structures determine the upward spiral toward psychological well-being that may follow after positive social media interactions (Fredrickson \& Joiner, 2002). Engaging in selfposting behavior, but also exposure to social media content posted by others is accordingly more likely to trigger positive outcomes if individuals possess the necessary adaptive emotional regulation strategies to maximize the enjoyment state (e.g., Palmer et al., 2016; Tugade \& Fredrickson, 2007).

\section{The Social Medía Literacy (SMILE) Model}

Ample studies have assessed the effectiveness of media literacy. For instance, it has been demonstrated that media literacy education can increase media knowledge and criticism, 
reduce media realism and diminish the influence of desirable media portrayals of social actors (Jeong et al., 2012; Vahedi, Sibalis, \& Sutherland, 2018). In addition, scant evidence exists on the actual decline/increase of negative media effects when media literacy increases (Vahedi et al., 2018; Xie, Gai, \& Zhou, 2019). Yet for social media, such evidence is missing which may be because no model exists that can explain the mechanisms relating to social media literacy. The SMILE-model was designed to map and understand such processes, and puts forward five assumptions that relate to empowering social media users (assumptions 1-2; see Figure 1) and developing social media literacy (assumptions 3-5; see Figure 1).

[Figure 1 here]

\section{Empowerment}

As for empowerment, the SMILE-model suggests two assumptions that directly build on the Differential Susceptibility to Media Effects Model (DSMM) (Valkenburg \& Peter, 2013), which integrates insights from renowned media effects theories and social psychology literature.

Assumption 1: Social media literacy as a moderator. Social media literacy is assumed to operate as a moderator in the relation between social media use and well-being. Social learning theory (Bandura, 2001), script theory (Wright, 2011), and media literacy theory (Potter, 2004) explain that when specific social media content conflicts with a user's cognitions, a negative well-being effect is less likely. Potentially harmful social media interactions will clash with the cognitive, and therefore also with the affective structures of literate users. As these users have a thorough understanding of the negative effects that one's own behaviors and certain content types of others could trigger, they are in control of their affective responses towards these behaviors and contents. Accordingly, they adaptively regulate the rare negative emotions that still occur. Also, users with advanced levels of social media literacy may only experience positive emotions in these situations as they are able to 
focus on the scarce positive aspects of these (undesirable) behaviors and contents (Buunk, Collins, Taylor, VanYperen, \& Dakof, 1990). Additionally, when users display behaviors or interact with content which inherently triggers positive effects, these effects may be even stronger among social media literate users as their elaborated cognitive and affective structures constantly help them to maximize their social media experiences.

Assumption 2. Social media literacy as a predictor. The DSMM (Valkenburg \& Peter, 2013) describes that the same factors that moderate relations between media use and wellbeing, may also affect how often a user is exposed to media messages in the first place. Accordingly, we assume that social media literacy as a predictor shapes social media content preferences, i.e., exposure to social media content of others and one's own social media behavior.

Considering exposure, social media literate users are likely to be less exposed to potentially adverse content than non-literate users. This manifests itself at two different levels. First, drawing on media selection theory (Klapper, 1960), social media literate users selectively chose from whom they view social media content. They critically evaluate the persons to whom they connect and mainly include peers and other known individuals instead of strangers (Trepte \& Reinecke, 2011). Therefore, their chances to come across potentially harmful messages are much smaller (e.g., Lup, Trub \& Rosenthal, 2015).

Second, even though users control whom is included in their online network, research suggests that the distinctive attributes of social media platforms still imply that "the content that people view in their social media feeds is largely outside of individual control" (Vraga, Bode, \& Troller-Renfree, 2016, p. 150). Therefore, unlike with traditional media consumption, the predictive power of social media literacy lies only partly in the selective non-exposure to content (Klapper, 1960) and manifests itself further at the level of attention processes. In this context, users contribute variable attention in function of how optimal the messages are; social 
media literate users intentionally pay little attention to potentially harmful content and more attention to potentially beneficial messages as they understand how they can be negatively vs positively affected by viewing certain posts (Vraga et al., 2016).

Considering one's own social media behavior, social media literate users are believed to engage in the social media environment relying on their elaborated cognitive and affective structures. Again, this manifests itself at two different levels. First, these users are well aware of the people that have access to their profile entries. As explained above, they mainly connect with known individuals and limit strangers' access (Trepte \& Reinecke, 2011). Moreover, as they know that not all content types are equally appropriate among different audiences (e.g., friends, family and professional relations), they apply advanced privacy control settings which limit the visibility of certain posts to specific connections (Trepte \& Reinecke, 2011). Consequently, social media literate users are much less likely to be negatively affected.

Second, users' level of social media literacy shapes the messages they share. Unlike with traditional media, social media users are constantly enabled to create, edit and share content themselves (Tsitsika et al., 2014). By drawing on media selection theory (Klapper, 1960), social media users are likely to carefully monitor the content they create and post in order to obtain wished-for beneficial emotions. Accordingly, these users succeed in balancing the need to share content, which helps accrue the benefits of social media usage, and the need to control this content, which minimizes the privacy risks related to sharing personal information online (Trepte \& Reinecke, 2011).

\section{Development}

By applying an ecological perspective (Bronfenbrenner \& Morris, 2006), the SMILEmodel argues that social media literacy develops through interactions between a person and his/her environment. Within this environment, several agents play an important role and do not exclusively refer to educators (i.e., formal agents) but also account for peers and family 
members (i.e., informal agents). As the literature traditionally considers formal agents and seems to position these agents as fundamentally different from family and peer socialization, a scholarly debate has taken place on how to understand different sources of people's (social) media literacy (Hobbs, 2011). The SMILE-model intends to help this debate move forward by arguing that both formal and informal agents contribute to social media literacy and conceptualizes a novel process labelled "the participatory mediation of social media literacy."

The process of participatory mediation is rooted within the autonomy-supportive parental mediation literature (Valkenburg, Piotrowski, Hermanns, \& de Leeuw's, 2013) and media literacy theory (Potter, 2004). High participatory mediation is received when an agent and an individual actively discuss social media topics in a way that helps the individual a) to understand its potential effects and b) to be in control of adopting desirable affective responses when using social media. Importantly, the agent acknowledges the person's thoughts and feelings during these active discussions. Low participatory mediation occurs when the agent transfers cognitive, and thereby also affective structures without any interaction. Participatory mediation can thus be considered on a continuum including more or less interactions between the agent and the individual. Based on self-determination theory (Deci \& Ryan, 1985), many interactions between the agent and the individual, in which the individual's perspective is actively taken into account, results in a better internalization of the received social media literacy structures.

To understand how participatory mediation relates to the development of social media literacy, the SMILE-model theorizes reciprocal, conditional and differential learning processes. Similar processes can occur for the development of more traditional forms of media literacy, yet the current paper aims to foreground social media peculiarities in each.

Assumption 3: Reciprocal processes. The relations between participatory mediation processes and social media literacy development are assumed to be reciprocal. An agent may 
mediate social media literacy among people. At the same time, when these people actively participate and exert agency in their development (Grusec \& Hastings, 2015), their responses to this mediation may shape future mediation messages received from the agent. Such reciprocal relations are drawn from Bandura's social cognitive theory (2001), but also are theorized in models such as the family systems framework (Broderick, 1993) and are especially likely to occur for high levels of participatory mediation. During active discussions, the messages of both members are likely to affect each other positively (Vandenbosch, 2018).

Assumption 4: Conditional processes. Bandura's model (2001) and socialization literature (Grusec \& Hastings, 2015) suggest that generally, different agents in the environment do not influence people as separate entities but operate simultaneously and may strengthen or weaken each other. Accordingly, it is believed that the development of social media literacy depends on the impact of one agent interacting with the influence of other agents. Such interactive processes have also been suggested for traditional media literacy as scholars have for instance argued that when educators and parents both promote media literacy, stronger skills are developed (Chakroff \& Nathanson, 2011).

Assumption 5: Differential learning processes. Finally, the model assumes that, depending on which agent is involved in the participatory mediation (e.g., educator, family member or peer), people develop different social media literacy competencies through differential types of learning processes (i.e., qualification and socialization). Following education literature (Biesta, 2006), we argue to distinguish between qualification and socialization agents. Through qualification, people acquire more formal social media literacy competencies. A prime example of an important qualification agent is an educator. Educators are typically teachers for young people, or researchers for older people, who deliver a formal media literacy intervention (Xie et al., 2019). During such an intervention, educators instruct on how to understand and evaluate media messages (Vahedi et al., 2018). A substantial amount 
of intervention studies has shown that such intensive formal training increases general media knowledge and critical thinking skills (Jeong et al., 2012; Vahedi et al., 2018).

Such interventions focus on low participatory mediation processes as these are often delivered in a one-to-many format and therefore do not leave room for active discussions. Also, they typically provide a highly valuable foundation to develop strong cognitive structures as educators are trained to accurately inform their audience. Such interventions are often very intense- - with time being carefully devoted to instruct.

However, there are also several downsides related to educator-based interventions. First, following literature on emotion regulation development (Morris, Silk, Steinberg. Myers, \& Robinson, 2007), educators are less likely than other agents (e.g., peers and parents) to stimulate affective structures. The learning of (adaptive) emotion regulation capabilities often occurs while experiencing emotions or by modeling other people's strategies after observing them in social media interactions (Morris et al., 2007). As it is unlikely that a person experiences strong emotions related to social media usage during a formal intervention or models the educator's own strategies to regulate emotions, educators are not suitable agents to mediate affective structures of social media literacy.

Second, the effects of these interventions are highly likely to fade in time. Priming literature argues that the lasting effect of a prime on a targeted behavior/thought/emotion is a product of its frequency and recency (Roskos-Ewoldsen, Roskos-Ewoldsen, \& Dillman Carpentier, 2002). In this view, participatory mediation processes that occur regularly and are close in time to people's social media behavior are most likely to stimulate the acquirement of social media literacy. Yet, as social media is normally not used during the formal educatorbased intervention (i.e., recency), and as these interventions are often highly intensive but occur only once (i.e., frequency), the cognitive structures are not developed strongly enough to be chronically accessible. Furthermore, educators, who typically use a protective approach to 
convert (social) media literacy messages, could face resistance as their approach often neglects users' own beliefs about- and emotional engagement with (social) media (Hobbs, 2011). This might hold especially true in a classroom setting in which young (social) media users resist the mediation messages received from their teachers.

Through socialization, people develop social media literacy more informally as they would acquire the knowledge/skills within the context of being/becoming a member of a social group. A prime example of such a socialization agent is peers. Especially young people attach considerable importance to the knowledge and values peers pass on to them. Therefore, peers are known to be the most important socialization agents in their lives (Grusec \& Hastings, 2015). Participatory mediation processes through peers (both low and high) provide individuals firstly with knowledge on different types of social media effects. People may informally transfer social media knowledge they acquired themselves to their friends. Also, peers may indirectly mediate affective structures. Emotion regulation theory explains that regulation strategies are learned by observing how others control particular emotions (Morris et al., 2007). As peers are the most straightforward agents to experience negative and positive emotions due to social media usage in the presence of an individual, this individual might learn to regulate one's own emotions by observing how peers deal with theirs.

Peer mediation strategies are expected to have (relatively) strong effects in terms of frequency and recency. First, peers are likely to regularly discuss social media and related emotions among each other (Yau \& Reich, 2018). Accordingly, people receive many (low or high participatory) mediation messages from peers (i.e., frequency). Also, these mediation messages seem to occur very close to the moment when social media literacy is actually needed as social media effects and related emotions can be discussed among peers while browsing their social media feeds (i.e., recency). Moreover, as people perceive peers as valuable information sources (Grusec \& Hastings, 2015), they are less likely to resist mediation messages coming 
from peers. However, the quality of peers' participatory mediation highly depends on peers' own social media literacy level. It could be, for instance, that peers with less elaborated levels give incorrect information or adopt maladaptive emotion regulation strategies when engaging with social media content themselves.

Lastly, family members are argued to mediate social media literacy amongst each other. On the one hand, parents can mediate social media literacy among their children. Specifically, they can take up both the role of a qualification and a socialization agent. The literature argues that parents can, similar to educators, qualify social media literacy (e.g., Daneels \& Vanwynsberghe, 2017). For instance, by formally providing social media knowledge, they may stimulate a critical disposition towards social media. Moreover, as parents intentionally 'teach' adaptive emotion regulation strategies (Morris et al., 2007), they are also likely to qualify affective social media literacy structures.

Some scholars question if parents have the same potential as trained educators to properly qualify media literacy competences (see for instance Hobbs, 2011). Accordingly, parents could also take up a more socializing role. In this interpretation, they could likewise provide their children with knowledge on social media effects. This transferred knowledge, however, is not guaranteed to be 'right' if, for instance, parents are less active social media users. Parents could also mediate affective structures; they could adopt more informal practices such as talking about experienced negative emotions and could help making sense of them. Consequently, children may learn to use their social media literacy knowledge to adaptively regulate their emotions when engaging with social media.

On the other hand, children are just as likely as their parents to be mediation agents of social media literacy. In this case, they mediate their parents' level of social media literacy. First, children can qualify their social media knowledge to their parents. As they often have more practical social media knowledge, they intentionally teach their less informed and skilled 
parents how to use social media platforms (e.g., Correa, Straubhaar, Spence, \& Chen, 2015). Yet, children can also take up a more socializing role. Children explain to their parents how they should interact within these platforms and which behaviors are thought appropriate (Van den Bulck, Custers \& Nelissen, 2016). Children have less potential to mediate affective social media literacy structures, though. Parents are less likely to seek advice from their children when facing negative emotions, they rather turn to other agents (e.g., life partner or a friend).

\section{An Application of the SMILE-model: The Positivity Bias and Adolescents' Social Media}

\section{Literacy}

Build-in platform features of social media (e.g., automatically showing pictureenhancing filters when posting a picture) facilitate the construction of positive content and thus the participation in the positivity bias (boyd \& Ellison, 2008; Sheldon \& Bryant, 2016; Walther, Van Der Heide, Ramirez, burgoon, \& Peña, 2015). Participation in the positivity bias in social media can be defined as the extent to which social media users strategically post self-related content which is typically highly selective, curated and unspontaneous as the goal of a positive self-presentation prevails over other goals of social media usage. A typical example of an unspontaneous post is someone who organizes a photoshoot of himself/herself with the sole purpose of selecting a good picture to post on social media. Often, the selected picture is curated or manipulated before being posted on social media. The social media post in which the selected and curated picture is featured is labelled to be unspontaneous.

A positivity bias in social media content especially occurs when presenting oneself on the platform to a larger audience as opposed to social media interactions with close friends (Yau \& Reich, 2018). The attractiveness of posting positively biased content is usually explained in the literature by the well-known theory of Goffman (1959). Goffman argued that individuals are intuitively concerned about how others perceive them and thus try to strategically manage and influence these perceptions. Especially adolescents are considered to 
take part in such impression management behavior as such behavior relates to their developmental needs. Adolescents are more dependent of peers than other developmental groups and are preoccupied with building a personal identity (Subrahmanyam \& Šmahel, 2011). In line with this reasoning, adolescents frequently use social media to present themselves to peers in a favorable way (e.g., Yau \& reich, 2018).

Because of the daily confrontations with the positivity bias and adolescents' developmental needs, social media literacy in this area may be particularly relevant. The previously presented definition of social media literacy implies that social media literate adolescents understand the implications of (positively) presenting oneself in social media environments. Moreover, they have cognitive and affective structures to handle the effects of the positivity bias. Drawing on the SMILE-model and literature on the positivity bias, the mechanisms explaining how social media literacy empowers adolescents and develops among them in regards of the positivity bias are described below. Several testable predictions follow from the integration of the literature that may be useful for future research.

Social Media Literacy and the Empowerment Process. Walther and colleagues (2015) noticed that users who exclusively received online positive information about another user were more likely to idealize this user. Festinger (1954) adds that exposure to idealization is typically followed by social comparison processes. Such upward comparisons result in either self-improvement motivations or negative self-effect. Self-improvement motivations typically occur for people who strongly feel in control over their personal outcomes (Buunk et al., 1990). As these people believe they can improve themselves and/or avoid failures, upward comparisons are not threatening for their self-views. Instead comparisons are very likely to be experienced as inspiring (Buunk \& Gibbons, 2007; Buunk et al., 1990).

As feeling in control over one's social media experiences is characteristic for social media literate users, the SMILE-model (assumption 1) argues that social media literacy 
determines which outcomes will occur resulting from comparison processes. Particularly, social media literate users are expected to be able to use the idealized content as a source of inspiration and may find a healthy dose of goodwill to improve oneself when using social media (Meier \& Schäfer, 2018). Consequently, upward comparison processes with positively biased presented users merely result in positive affect (Buunk \& Gibbons, 2007) which maximizes the positive experience of exposure. Moderate literate social media users are specifically expected to try to adaptively control negative emotions, such as jealousy and envy, resulting from upward comparison processes. For the other least literate users, the comparisons may negatively affect their self-views as they are less in control of their social media experiences.

Furthermore, social media literate adolescents will progress their own positively biased self-posting behaviors differently. Self-perception theory postulates that self-effects occur because people derive particular self-concepts from prior behavior (Bem, 1972). If the derived self-concepts are in line with (or only mildly deviate from) their current self-concept, individuals are theorized to maximize the strength of the consistency between those two selfconcepts. This can be done by adapting their subsequent behaviors, cognitions and beliefs (Valkenburg, 2017). If the derived self-concepts deviate from one's true self-concept, a discrepancy will occur and trigger adverse consequences, such as a lowered self-esteem and depressed feelings (Higgins, 1987).

In general, the literature has shown that adolescents who do not act true to themselves in their day-to-day interactions are much more likely to experience harmful identity discrepancies (Harter, 1997) and that such problems are more severe for adolescents who are not able to adaptively control their behaviors and emotions (Harter, Marold, Whitsell, Cobbs, 1996). Similarly, social media research has found that young adults who are experiencing emotional instability - and are thus unable to adaptively control emotions - are more frequently 
engaging in online false self-presentations (Michikyan, Dennis, \& Subrahmanyam, 2015) which may result in negative well-being consequences (Gil-Or, Levi-Belz, \& Turel, 2015).

According to this literature, the social media literacy definition (see section) and the SMILE-model, social media literate adolescents are expected to post a "best version" of themselves online, but this version will still be in line with whom they truly are. As a result, they feel even more positive about themselves over time (see the research of Reinecke and Trepte (2014) for initial support on this reasoning). The reverse can be expected for less social media literate adolescents as they could easily experience an identity discrepancy because their positively biased content does not reflect their true selves. As these less literate persons are also not able to adaptively control the negative emotions that come along with the identity discrepancies, negative well-being outcomes are triggered.

Although social media literate adolescents may also post (highly) biased content, the SMILE-model expects this is rather unlikely (assumption 2). As social media literate users know how extremely biased self-presentations could negatively affect oneself, they proficiently construct a self-presentation which reflects for the most part their natural self. These self-presentations can to some extent be a reflection of a better version of the self in order to boost positive affect and self-confidence.

Also, posting positively biased content online inherently involves sharing personal information. In this context, "the nature and the publicity of disclosed personal information has to be co-interpreted as a psychological trade-off between "the need to be seen" and the awareness of possible privacy issues" (Trepte \& Reinecke, 2011, p. 185). In other words, social media literate users know that they will not be able to get all benefits out of their social media experiences when posting too little positive information whereas posting too much information brings along enormous privacy risks. Therefore, social media literate users are capable of pondering the opportunities and risks of positive online self-presentations and to make use of 
different strategies to achieve a precarious balance in this regard. These users probably avoid sharing information that includes privacy risks (e.g., leaving for a holiday) and rather share indirect personal details (e.g., disclosing that one is passionate about travelling) (Trepte \& Reinecke, 2011).

Moreover, social media literate adolescents may differently select social media content. By limiting their connections to strangers, these adolescents protect themselves in a first step from potential negative effects of positively biased content. Research has suggested that positive posts from strangers are especially likely to trigger adverse upward comparison processes (de Vries, Möller, Wieringa, Eigenraam \& Hamelink, 2018). Yet, avoiding content of strangers will not be sufficient to avoid exposure to the positivity bias, as a vast number of social media users present themselves in a highly positive light (e.g., Yau \& Reich, 2018). As social media literate adolescents understand how such imagery can negatively affect them, they are expected to make the conscious decision to spend little attention on such posts (Vraga et al., 2016).

\section{Social Media Literacy and the Development Process.}

Contemporary literature on the positivity bias has highly neglected how literacy regarding this bias is developed. The SMILE-model's assumptions and the literature on interactions about social media topics may help to understand how such processes develop. This literature suggests that adolescents discuss the positivity bias with different agents in their environment (Fant, Schreurs, \& Vandenbosch, 2019; Yau \& Reich, 2018), yet research has mainly illustrated the existence of peer discussion about this topic. This gap is somewhat surprising as researchers have explicitly recommended parents and educators to discuss the positivity bias with children (van Driel, Pouwels, Beyens, Keijsers, \& Valkenburg, 2019). The SMILE-model highlights that not all agents have the same potential to mediate social media literacy (assumption 5). 
Peers seem the most promising agents as they, more than any other agent, function as experts in this area (Yau \& Reich, 2018). Research has indicated that adolescents are highly aware of other peers struggling with exposure to and the self-posting of positively biased content (Verlinden, Schreurs, \& Vandenbosch, 2019). Moreover, some peers are seen as highly knowledgeable in this area and are even explicitly consulted for advice on social media behavior. Also, adolescents indicate to share emotions that have been triggered by the positivity bias with peers and thus it can be expected they learn emotion regulation strategies from their peers (Verlinden et al., 2019). Yet, peers' potential as a successful mediation agent depends on the accuracy and correctness of their own social media literacy.

In this sense, the participatory mediation messages of educators are more likely to transfer correct and accurate information on positivity bias effects. The study of Mclean and colleagues (2016) indeed showed that an educator-based intervention on positively biased appearance-related content increased cognitive media literacy skills. However, this type of mediation is expected to be rather short-term in nature according to the SMILE model.

In one of the rare studies on parents (Fant et al., 2019), only a small number of the adolescent interviewees indicated that their parents actively taught them positivity bias knowledge. Presumably, that is due to parents' limited literacy in this area. Parents are less likely to invest in online impression management behavior as such behavior is less prevalent among older people (e.g., Dhir, Pallesen, Torsheim, \& Andreassen, 2016). Sharenting research also showed that parents have limited positivity bias understandings. Parents often post childrelated content which is found embarrassing by the child and even harmful for his/her online identity (Verswijvel, Walrave, Hardies, \& Heirman, 2019).

Consequently, children may strongly feel they are more expert in this area than their parents and therefore, it seems much more likely that children teach their parents positivity bias knowledge. Such processes are often referred to in the literature as the child-effect (Van den 
Bulck, et al., 2016). In support of this, research shows that children sometimes instruct their parents on the appropriateness of social media posts (Fant et al., 2019). Such child mediation messages may result in novel cognitive structures among parents. Subsequently, the increased literacy may make parents more insightful in their children's positively biased content and as a result, they are more likely to stimulate social media literacy among their children. This example illustrates how reciprocal processes could take place in the development of social media literacy (assumption 3).

Moreover, the SMILE model expects that this mediational impact will be dependent of the interaction with other agents (assumption 4). Indeed, research shows adolescents frequently discuss the positivity bias with peers (Yau \& Reich, 2018) and, to a lesser extent, with educators. The congruence between the different discussions will determine the extent to which literacy will be developed. For instance, the impact of an active classroom discussion about how to control jealousy when being exposed to idealized Instagram images may be heightened/reduced when an adolescent encounters similar/opposite messages coming from valued peers.

\section{Directions for Future Research}

Given the ubiquity of social media (Anderson \& Jiang, 2018), it is surprising that no attempts were made to formulate a role for social media literacy in users' well-being. The SMILE-model, as a first guiding framework for social media literacy, addresses such fundamental shortcomings in media literacy and media effects literature by modeling an empowering and a development process of social media literacy. As the model connects two subfields in communication studies that have seldom been related before, it may contribute to the fast-developing field of social media literacy in several important ways.

Particularly, future research drawing on the SMILE-model will reveal whether the inclusion of social media literacy increases the power of the social media/well-being model to 
explain negative and positive outcomes among users. Moreover, such research will tackle the underexplored, mutually influencing mediation processes of several agents in the development of social media literacy. It will be disclosed whether a dynamic and interactive approach towards multiple agents allows for a more detailed understanding on the complex learning of social media literacy.

Importantly, research that addresses these novel matters should consider different research designs. Qualitative research could, for instance, provide some first insights about the present cognitive and affective structures when young users engage in different social media areas and how they develop such structures. Such insights will be particularly helpful to construct new measurement instruments for social media literacy and social media behaviors which are needed in survey research. Other research designs may also prove useful to gain a deeper understanding of several assumptions of the framework. For instance, eye-tracking research could discover the amount of attention social media literate users pay to harmful vs beneficial social media content (i.e., assumption 2).

Notably, some groups of people may be more likely than others to develop social media literacy and to use these structures when interacting with social media. For example, a strong need for cognition (Cacioppo \& Petty, 1982) would facilitate the development of cognitive structures when receiving mediation messages. Future research should carefully consider such important individual differences when exploring the model assumptions.

Finally, the field of traditional media literacy has typically been developed for young media users as researchers but also policymakers and the public have been concerned about the significant role of mass media in their development (Potter, 2020). The same is likely to happen for the social media literacy field as children and adolescents are the most intense consumers of social media (Anderson \& Jiang, 2018) and social media are at the heart of contemporary youth development. Consequently, social media seem to affect these age groups the most 
profoundly (Kleemans et al., 2018; Van Driel et al., 2019). In this respect, the SMILE-model especially serves as a theoretical backdrop for scholars who are engaged in the study of media in the lives of children and adolescents. Specifically, we hope that the SMILE-model will spark research lines among these scholars that examine how social media literacy can enrich the lives of this developmental group.

One important research line inspired by the SMILE-model concerns the rethinking of (social) media literacy interventions. All too often, such interventions are implemented without a previous understanding of the competencies needed to counter specific (social) media effects. Such an understanding is the first necessary step to develop interventions which adequately target the appropriate competencies among young social media users. 


\section{References}

Anderson, M., \& Jiang, J. (2018, May 31). Teens, social media and technology, 2018. Pew Research Center. Retrieved from http://www.pewinternet.org/2018/05/31/teenssocial-media-technology-2018/

Aufderheide, P. (1993). Media literacy: A report of the national leadership conference on media literacy. Aspen, CO: Aspen Institute.

Austin, E. W., \& Pinkleton, B. E.. (2016). The viability of media literacy in reducing the influence of misleading media messages on young people's decision-making concerning alcohol, tobacco, and other substances. Current Addiction Reports, 3, 175181. doi:10.1007/s40429-016-0100-4

Bandura, A. (2001). Social cognitive theory of mass communication. Media Psychology, 3, 265-299. doi:10.1207/S1532785XMEP0303_03

Bem, D. J. (1972). Self-perception theory. In L. Berkowitz (Ed.), Advances in experimental social psychology (pp. 1-62). New York, NY: Academic Press.

Biesta, G. (2006). Beyond learning: Democratic education for a human future. Boulder: Paradigm Publishers.

boyd, D. M., \& Ellison, N. B. (2008). Social network sites: Definition, history, and scholarship. Journal of Computer-Mediated Communication, 13, 210-230. doi:10.1111/j.1083-6101.2007.00393.x

Broderick, C. B. (1993). Understanding family process: Basics of family systems theory. Thousand Oaks, CA: Sage Publications, Inc.

Bronfenbrenner, U. \& Morris, P. A. (2006). The bioecological model of human development. In W. Damon \& R. M. Lerner (Eds.), Handbook of child psychology: Theoretical models of human development (pp. 793-828). New York, NY: Wiley. 
Buunk, A. P., \& Gibbons, F. X. (2007). Social comparison: The end of a theory and the emergence of a field. Organizational Behavior and Human Decision Processes, 102, 3-21. doi:10.1016/j.obhdp.2006.09.007

Buunk, B. P., Collins, R. L., Taylor, S. E., VanYperen, N. W., \& Dakof, G. A. (1990). The affective consequences of social comparison: Either direction has its ups and downs. Journal of Personality and social Psychology, 59, 1238-1249.

Byrne, S. (2009). Media literacy interventions: What makes them boom or boomerang? Communication Education, 58, 1-14. doi:10.1080/03634520802226444

Cacioppo, J. T. \& Petty, R. E. (1982). The need for cognition. Journal of Personality and Social Psychology, 42, 116-131.

Chakroff, J. L., \& Nathanson, A. I. (2011). Parent and school interventions: Mediation and media literacy. In S. L. Calvert \& B. J. Wilson R. D. (Eds.), The handbook of children, media, and development (p. 552-576). Malden: Wiley-blackwell

Correa, T., Straubhaar, J. D. Chen, W., \& Spence, J. (2015). Brokering new technologies: The role of children in their parents' usage of the internet. New Media \& Society, 17, 483-500. doi:10.1177/1461444813506975

Cracco, E., Goossens, L., \& Braet, C. (2017). Emotion regulation across childhood and adolescence: Evidence for a maladaptive shift in adolescence. European Child \& Adolescent Psychiatry, 26, 909-921. doi:10.1007/s00787-017-0952-8

Daneels, R., \& Vanwynsberghe, H. (2017). Mediating social media use: Connecting parents' mediation strategies and social media literacy. Cyberpsychology: Journal of Psychosocial Research on Cyberspace, 11. doi:10.5817/CP2017-3-5

de Vries, D. A., Möller, A. M., Wieringa, M. S., Eigenraam, A. W., \& Hamelink, K. (2018). Social comparison as the thief of joy: Emotional consequences of viewing strangers' 
Instagram posts. Media Psychology, 21, 222-245.

doi:10.1080/15213269.2016.1267647

Deci, E. L., \& Ryan, R. M. (1985). Intrinsic motivation and self-determination in human behavior. New York: Plenum.

Dhir, A., Pallesen, S., Torsheim, T., \& Andreassen, C. S. (2016). Do age and gender differences exist in selfie-related behaviours? Computers in Human Behavior, 63, 549-555. doi:10.1016/j.chb.2016.05.053

Fant, J., Schreurs, L., \& Vandenbosch, L. (2019). Familiedynamieken in sociale mediawijsheid: Een onderzoek naar de rol van de familiecontext in de ontwikkeling van sociale mediawijsheid bij adolescenten. (Unpublished master's thesis). KU Leuven, Belgium.

Festinger, L. (1954). A theory of social comparison processes. Human Relations, 7, 117-140. doi:10.1177/001872675400700202

Fredrickson, B., L., \& Joiner, T. (2002). Positive emotions trigger upward spirals toward emotional well-Being. Psychological Science, 13, 172-175. doi:10.1111/14679280.00431

Gil-Or, O., Levi-Belz, Y., \& Turel, O. (2015). The “Facebook-self”: characteristics and psychological predictors of false self-presentation on Facebook. Frontiers in Psychology, 6, 1-10. doi:10.3389/fpsyg.2015.00099

Gill, R. (2012). Media, Empowerment and the "sexualization of culture" debates. Sex Roles, 66, 736-745. doi:10.1007/s11199-011-0107-1

Goffman, E. (1959). The presentation of self in everyday life. New York, NY: Anchor.

Grusec, J. E., \& Hastings, P. D. Handbook of socialization: Theory and research. New York, London: The Guilford Press. 
Harter, S. (1997). The personal self in social context: Barriers to authenticity. In R. D. Ashmore \& L. Jussim (Eds.), Self and Identity: Fundamental issues (p. 81-105). New York: Oxford University Press.

Harter, S., Marold, D. B., Whitesell, N. R., \& Cobbs, G. (1996). A model of the effects of perceived parent and peer support on adolescent false self behavior. Child Development, 67, 360-374. doi:10.1111/j.1467-8624.1996.tb01738.x

Higgins, E. T. (1987). Self-discrepancy: A theory relating self and affect. Psychological Review, 94, 319-340. doi:10.1037/0033-295X.94.3.319

Hobbs, R. (2011). The state of media literacy: A response to Potter. Journal of Broadcasting and Electronic Media, 55, 601-604. doi:10.1080/08838151.2011.597594

Jeong, S., Cho, H., \& Hwang, Y. (2012). Media literacy interventions: A meta-analytic review. Journal of Communication, 62, 454-472. doi:10.1111/j.14602466.2012.01643.x

Klapper, J. T. (1960). The effects of mass communication. New York: Free Press

Kleemans, M., Daalmans, S, Carbaat, I., \& Anschütz, D. (2018). Picture perfect: The direct effect of manipulated Instagram photos on body image in adolescent girls. Media Psychology, 21, 93-110. doi:10.1080/15213269.2016.1257392

Lang, A. (2017). Limited capacity model of motivated mediated message processing. In C. Hoffner, \& L. van Zoonen (Eds.), The International Encyclopedia of Media Effects (pp. 1-9). Malden, MA: John Wiley \& Sons, Inc.

Livingstone, S. (2014). Developing social media literacy: How children learn to interpret risky opportunities on social network sites. Communications, 39, 283-303. doi:10.1515/commun-2014-0113

Lup, K., Trub, L., \& Rosenthal, L. (2015). Instagram \#Instasad?: Exploring associations among Instagram use, depressive symptoms, negative social comparison, and 
strangers Followed. Cyberpsychology, Behavior and Social Networking, 18, 247-252. doi:10.1089/cyber.2014.0560

McLean, S. A. Paxton, S. J., \& Wertheim, E. H. (2016). Does media literacy mitigate risk for reduced body satisfaction following exposure to thin-ideal media? Journal of Youth and Adolescents, 45, 1678-1695. doi:10.1007/s10964-016-0440-3

Meier, A., \& Schäfer, S. (2018). The positive side of social comparison on social network sites: How envy can drive inspiration on Instagram. Cyberpsychology, Behavior, and Social Networking, 21, 411-417. doi:10.1089/cyber.2017.0708

Michikyan, Dennis, \& Subrahmanyam (2015). Can you guess who I am? Real, ideal, and false self-presentation on Facebook among emerging adults. Emerging Adulthood, 3, 55-64. doi:10.1177/2167696814532442

Morris, A. S., Silk, J. S., Steinberg, L., Myers, S. S., \& Robinson, L. R. (2007). The role of the family context in the development of emotion regulation. Social Development, 16, 361-388. doi:10.1111/j.1467-9507.2007.00389.x

doi:10.1080/1369118X.2017.1281993

Palmer, C. A., Ramsey, M. A., Morey, J. N., \& Gentzler, A. L. (2016). How do people share their positive events? Individual differences in capitalizing, bragging, and masssharing. Journal of Individual Differences, 37, 250-259. doi:10.1027/1614$0001 / \mathrm{a} 000212$.

Perloff, R. M. (2014). Social media effects on young women's body image concerns: Theoretical perspectives and an agenda for research. Sex Roles, 71, 363-377. doi:10.1007/s11199-014-0384-6

Potter, W. J. (2004). Theory of media literacy: A cognitive Approach. Thousand Oaks, CA: Sage.

Potter, W. J. (2020). Media literacy: Ninth edition. Thousand Oaks, CA: Sage. 
Reinecke, L., \& Trepte, S. (2014). Authenticity and well-being on social network sites: A two-wave longitudinal study on the effects of online authenticity and the positivity bias in SNS communication. Computers in Human Behavior, 30, 95-102. doi:10.1016/j.chb.2013.07.030

Roskos-Ewoldsen, D. R., Roskos-Ewoldsen, B., \& Dillman Carpentier, F. R. (2002) Media priming: a synthesis. In J. Bryant \& D. Zillman (Eds.), Media effects: Advances in theory and research (pp. 97-120). Lawrence Erlbaum Associates, Publishers: London.

Sheldon, P., \& Bryant, K. (2016). Instagram: Motives for its use and relationship to narcissism and contextual age. Computers in Human Behavior, 58, 89-97. doi:10.1016/j.chb.2015.12.059

Subrahmanyam, K., \& Šmahel, D. (2011). Digital youth: The role of media in development. New York: Springer.

Tamplin, N., Mclean, S. A., \& Paxton, S. J. (2018). Social media literacy protects against the negative impact of exposure to appearance ideal social media images in young adult women but not men. Body Image, 26, 29-37. doi:10.1016/j.bodyim.2018.05.003

Trepte, S., \& Reinecke, L. (2011). Privacy online: Perspectives on privacy and selfdisclosure in the social web. New York: Springer.

Tsitsika, A. K., Tzavela, E. C., Janikian, M., Ólafsson, K., Iordache, A., Schoenmakers, T. M., Tzavara, C., \& Richardson, C. (2014). Online social networking in adolescence: Patterns of use in six European countries and links with psychosocial functioning. Journal of Adolescent Health, 55, 141-147. doi:10.1016/j.jadohealth.2013.11.010

Tugade, M. M., \& Fredrickson, B. L. (2007). Regulation of positive emotions: Emotion regulation strategies that promote resilience. Journal of Happiness Studies, 8, 311333. doi:10.1007/s10902-006-9015-4 
Vahedi, Z., Sibalis, A., \& Sutherland, J. E. (2018). Are media literacy interventions effective at changing attitudes and intentions towards risky health behaviors in adolescents? A meta-analytic review. Journal of Adolescence, 67, 140-152. doi:10.1016/j.adolescence.2018.06.007

Valkenburg, P. M. (2017). Understanding self-effects in social media. Human Communication Research, 43, 477-490. doi:10.1111/hcre.12113

Valkenburg, P. M., \& Peter, J. (2013) The differential susceptibility to media effects model. Journal of Communication, 63, 221-243. doi:10.1111/jcom.12024

Valkenburg, P. M., Piotrowski, J. T., Hermanns, J., \& de Leeuw, R. (2013). Developing and validating the perceived parental media mediation scale: A self-determination perspective. Human Communication Research, 39, 445-469. doi:10.1111/hcre.12010

Van den Bulck, J., Custers, K., \& Nelissen, S. (2016). The child-effect in the new media environment: Challenges and opportunities for communication research. Journal of Children and Media, 10, 30-38. doi:10.1080/17482798.2015.1121897

van Driel, I. I., Pouwels, J. L., Beyens, I., Keijsers, L., \& Valkenburg, P. M. (2019). 'Posten, scrollen, appen en snappen': Jongeren (14-15 jaar) en social media in 2019, Center for Research on Children, Adolescents, and the Media (CcaM), Universiteit van Amsterdam.

Vandenbosch, L. (2018). Sexual socialization. In T., Shackelford \& V., Weekes-Shackelford. Encyclopedia of Evolutionary Psychological Science. Springer

Vanwynsberghe, H. (2014). How users balance opportunity and risk: A conceptual exploration of social media literacy and measurement. Ghent University. Faculty of Political and Social Sciences, Ghent, Belgium

Verlinden, E., Schreurs, L., \& Vandenbosch, L. (2019). Schone schijn op sociale media: Een verkennend onderzoek naar de constructie van een positief vertekend beeld op sociale 
media en naar de ontwikkeling van sociale mediawijsheid bij adolescenten. (Unpublished master's thesis). KU Leuven, Belgium.

Verswijvel, K., Walrave, M., Hardies, K., \& Heirman, W. (2019). Sharenting, is it a good or a bad thing? Understanding how adolescents think and feel about sharenting on social network sites. Children and Youth Services Review, 104, 1-10.

doi:10.1016/j.childyouth.2019.104401

Vraga, E., Bode, L., \& Troller-Renfree, S. (2016) Beyond self-reports: Using eye tracking to measure topic and style differences in attention to social media content, Communication Methods and Measures, 10, 149-164. doi:10.1080/19312458.2016.1150443

Walther, J. B. (2017). The Merger of mass and interpersonal communication via new media: Integrating metaconstructs. Human Communication Research, 43, 559-572. doi:10.1111/hcre.12122

Walther, J. B., Van Der Heide, B., Ramirez, A., Burgoon, J. K., \& Pena, J. (2015). Interpersonal and hyperpersonal dimensions of computer-mediated communication. In Sundar, S. S. (Ed.), The handbook of the psychology of communication technology (pp. 3-23). Chichester, UK: John Wiley \& Sons.

Xie, X., Gai, X., Zhou, Y. (2019). A meta-analysis of media literacy interventions for deviant behaviors. Computers \& Education, 139, 146-156. doi:10.1016/j.compedu.2019.05.008

Yau, J. C., \& Reich, S. M. (2018). "It's just a lot of work": Adolescents' self-presentation norms and practices on Facebook and Instagram. Journal of Research on Adolescence, 1-14. doi:10.1111/jora.12376 


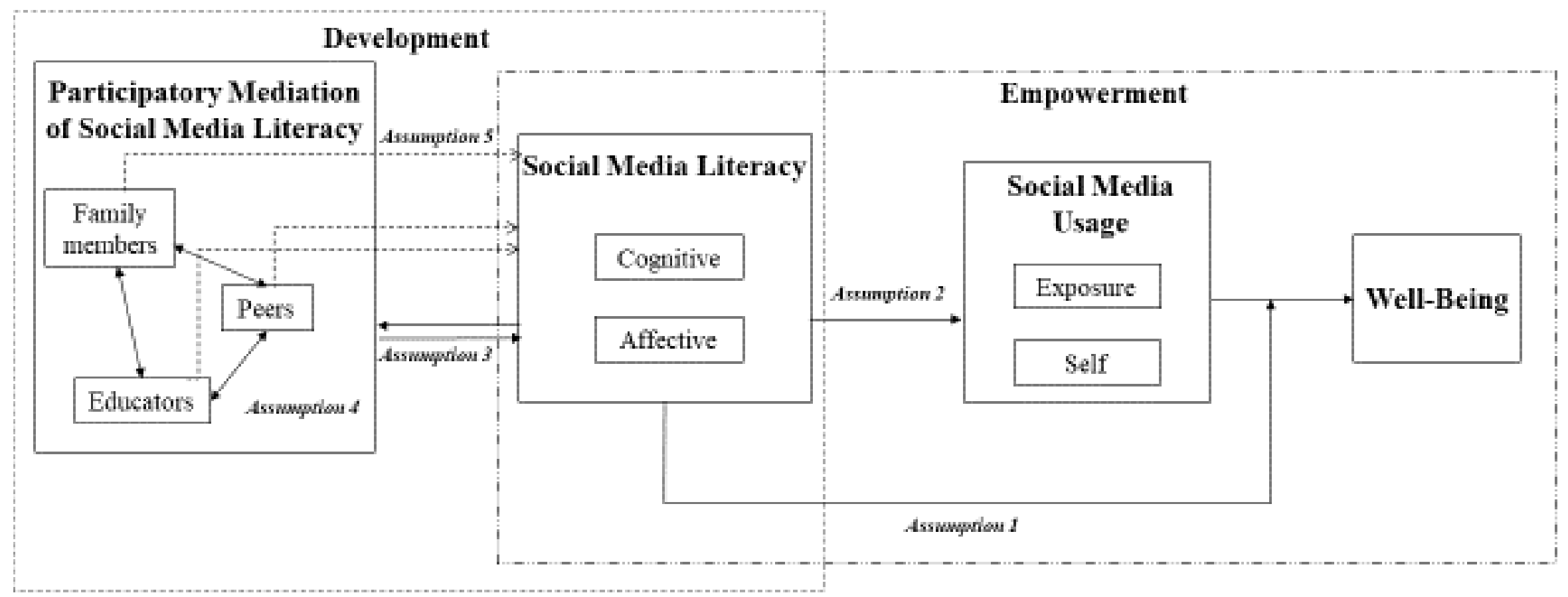

Assumption 1: Social media literacy operates as a moderator in the relation between social media usage and well-being Assumption 2: Social media literacy operates as a predictor of social media usage

Assumption 3: The relations between participatory mediation and social media literacy are reciprocal

Assumption 4: The impact of the participatory mediation of one agent is conditional on other's agents participatory mediation

Assumption 5: Depending on which agent is involved in the participatory mediation (i.e., educator, family member or peer), different social media literacy competencies are developed through differential types of learning processes (i.e., qualification vs socialization) 
